\title{
Contrasts in older persons' experiences and significant others' perceptions of existential loneliness
}

\section{Helena Larsson}

Malmö University, Sweden; Kristianstad University, Sweden

\author{
Anna-Karin Edberg \\ Kristianstad University, Sweden
}

\section{Ingrid Bolmsjö and Margareta Rämgård}

Malmö University, Sweden

\begin{abstract}
Background: As frail older people might have difficulties in expressing themselves, their needs are often interpreted by others, for example, by significant others, whose information health care staff often have to rely on. This, in turn, can put health care staff in ethically difficult situations, where they have to choose between alternative courses of action. One aspect that might be especially difficult to express is that of existential loneliness. We have only sparse knowledge about whether, and in what way, the views of frail older persons and their significant others concerning existential loneliness are in concordance.

Objective: To contrast frail older $(>75)$ persons' experiences with their significant others' perceptions of existential loneliness.

Methods: A case study design was chosen for this study. Individual interviews with frail older persons $(n=15)$ and interviews with their significant others $(n=19)$, as well as field notes, served as a basis for the study. A thematic analysis was used to interpret data.

Ethical considerations: This study was conducted in accordance with the principles of research ethics. Findings: The findings showed three themes: (I) Meaningless waiting in contrast to lack of activities, (2) Longing for a deeper connectedness in contrast to not participating in a social environment and (3) Restricted freedom in contrast to given up on life.

Discussion: Knowledge about the tensions between older persons' and their significant others' views of existential loneliness could be of use as a basis for ethical reflections on the care of older people and in the encounter with their significant others.

Conclusion: It is of importance that health care professionals listen to both the frail older person and their significant other(s) and be aware of whose voice that the care given is based on, in order to provide care that is beneficial and not to the detriment of the older person.
\end{abstract}

\section{Keywords}

case study, existential loneliness, frail older person, significant other, thematic analysis 


\section{Introduction}

As frail older people might have difficulties in expressing themselves, their needs and symptoms often have to be interpreted by others. One such, and subtle, issue is that of existential loneliness, which is difficult to interpret and detect. Significant others, such as family and friends, are frequently described as important advisors ${ }^{1}$ and decision-makers ${ }^{1-3}$ and health care staff often need to rely on their information. It is, of course, of great importance to involve and listen to significant others, ${ }^{4-6}$ but if their view differs from that of the older person, it can put health care staff in ethically difficult situations, where they have to choose between alternative courses of action. ${ }^{7}$ We have, however, only sparse knowledge about whether, and in what way, significant others' and older people's views of existential loneliness are in concordance. Such knowledge can be highly important for care provision, not only in the case of existential loneliness as such but also from a wider perspective concerning the weight that health care professionals give to information from different sources.

Paul Tillich ${ }^{8}$ and Viktor Frankl ${ }^{9}$ describe an existential dimension of loneliness as a phenomenon that belongs to life. ${ }^{10}$ Furthermore, the psychotherapist Irvin Yalom, ${ }^{10}$ who has explored existential concerns in human beings' lives, has referred to existential loneliness as a stipulation of life and pointed to how life itself involves existential loneliness. He describes what he calls 'the ultimate concerns', such as the inevitability of death, our need of freedom and belongingness and our search for meaning, ${ }^{10}$ which are all connected to existential loneliness, sometimes referred to as existential isolation, ${ }^{10}$ existential anxiety ${ }^{8}$ or existential distress. $^{9,11}$ More recently, existential loneliness has been explored in two reviews and described as a complex and unclear phenomenon. ${ }^{12,13}$ The literature review by Mayers and Svartberg ${ }^{12}$ describes exis- $^{-}$ tential loneliness as a basic sense of loneliness that occurs when we, as human beings, face that we are separated and alone in the world despite having other people around. The other review concludes existential loneliness as a fundamental condition of human life, intertwined with feelings of nothingness and emptiness. ${ }^{13}$ In addition, existential loneliness has been empirically studied in different health care contexts, for example, in palliative care ${ }^{14}$ in the care of people with aphasia, ${ }^{15}$ among women living with HIV,${ }^{12}$ and among frail older people ${ }^{16}$ and their significant others. ${ }^{17}$ One part of life when existential issues seem especially evident is in old age when thoughts like 'life is completed and no longer worth living' come to the fore, ${ }^{18}$ as well as thoughts of death and dying, ${ }^{19}$ and such experiences relate to existential loneliness. ${ }^{14}$ Frail older people have described existential loneliness as being related to feeling trapped in a frail and deteriorating body, being met with indifference, having nobody to share life with, and lacking purpose and meaning, ${ }^{16}$ while their significant others have described the older person's existential loneliness in terms of being disconnected from the outside world. ${ }^{17}$ One conclusion that can be drawn from these studies is that existential loneliness is a phenomenon that involves a range of feelings and expressions that might be interpreted differently by different people.

In the care of frail older people, significant others often have to act as representatives for the older person at the end of life. ${ }^{1}$ They can also function as an important link between the older person's former and present situation. ${ }^{4}$ However, an interview study with family members concluded that there is an underlying risk that they often, instead of listening to the older person's own wants and wishes, make decisions based upon trust, type of relationship and available information, which can all be influenced by the caring culture and the communication in the family. ${ }^{2}$ In addition, health care staff have to navigate between the older person, their significant other(s), the organisation, laws and not least their own moral and ethical approach ${ }^{20}$ to do good and not harm. ${ }^{21}$ This is not an easy task, especially when facing such an unclear and complex phenomenon as existential loneliness. Studies have shown that health professionals find it challenging to encounter existential distress among persons with advanced cancer ${ }^{11}$ and existential loneliness among frail older persons. ${ }^{22}$ Furthermore, studies show that health care staff provide care based upon what they believe is best for the patient, sometimes without even asking the patient. ${ }^{3}$ This also becomes visible in results from 
studies using proxy ratings, that is, when someone else, for example, significant others or health care staff, rates the patient's symptoms. Studies focusing on comparisons of self- and proxy assessments of pain ${ }^{23}$ and proxy ratings of quality of life among patients with dementia ${ }^{24}$ show that the ratings differ and that even people who state that they know the older person well do not really know him or her. There is, therefore, a need for a deeper understanding of these differences in order to guide health care professionals in the provision of care.

The present study has its starting point in two previous studies from the existential loneliness study (LONE study). ${ }^{25}$ The LONE study is on the development phase of a complex intervention, ${ }^{26}$ where existential loneliness is explored through interviews with frail older people, ${ }^{16}$ their significant others, ${ }^{17}$ and health care staff. ${ }^{22}$ The aim of this study was to contrast frail older $(>75)$ persons' experiences with their significant others' perceptions of existential loneliness.

\section{Methods and material}

\section{Design}

The present study has its starting point in two previous studies, one with frail older persons' experiences of existential loneliness ${ }^{16}$ and the other regarding significant others' interpretations of the older person's existential loneliness. ${ }^{17}$ Since the two first studies focused on experiences and perceptions, respectively, and this study aimed to explore contrasts, we used an inductive approach in a secondary analysis of these interviews. A case study design was chosen since the intention was to present a complete description of the phenomenon within its social context and answer the questions of 'how' and 'why'. ${ }^{27}$ Individual interviews with frail older persons and interviews with their significant others, as well as field notes, served as a basis for analysis. Since a case study is a method for structure rather than a method for analysis, ${ }^{27}$ a thematic analysis ${ }^{28}$ served as a tool to interpret the data. The thematic analysis made it possible to search for themes and patterns in the data and to contrast experiences and perceptions.

\section{Setting}

The concept 'frail older people' was defined as older ( $>75)$ persons, late in life and dependent on long-term care or services related to health problems. The word 'frail' relates in this study, as well as in the LONE study, ${ }^{25}$ to a frail physical body due to illness and physical impairments. The care was given by formal caregivers from the municipality or the county council. In order to attain variation, persons from different care contexts were interviewed: Primary health care centre, Municipal home care, Residential care, Hospital, Specialised palliative home care and Specialised palliative ward. Data were collected in the southern part of Sweden.

\section{Data collection}

Three separate data collections served as a basis for this case study: individual interviews with frail older people $(n=15)$, interviews with one or more of their significant others $(n=19)$ and the researchers' field notes from the interviews with the older persons. Saturation was reached when the researchers who did the interviews assessed that nothing additional of relevance for the study came up in the interviews. In total, 23 older persons were interviewed. ${ }^{16}$ Since the aim of this study was to contrast experiences and perceptions, it was necessary to use paired interviews which consisted of one older person and his or her significant others. Therefore, it was only possible to use 15 of the 23 interviews with the older persons since they were the ones who had designated a significant other. 
Table I. Characteristics of the sample.

\begin{tabular}{lc}
\hline Older persons & $n=15$ \\
\hline Men/women & $7 / 8$ \\
Age: median (range) & 86 (76-10I) \\
Care context & \\
$\quad$ Primary health care centre & 4 \\
Municipal home care & 2 \\
Residential care & 4 \\
Hospital & 1 \\
Specialised palliative ward & 1 \\
Specialised palliative home care & 3 \\
Living in ordinary housing & 11 \\
Living in a nursing home & 4 \\
\hline Significant others & $\mathrm{n}=19$ \\
\hline Men/women & $6 / 13$ \\
Age: median (range) & $(49-86)$ \\
Sons/daughters & $5 / 4$ \\
Sibling & $\mathrm{I}$ \\
Friend & 1 \\
Daughter-in-law & $\mathrm{I}$ \\
Wives & 4 \\
Cousin's wife & 1 \\
Nieces & 2 \\
\hline
\end{tabular}

Interviews with older persons. The older persons were identified by a designated contact person at each care unit who provided oral and written information about the study. If the older person gave his or her permission, his or her name was communicated to one of the co-workers who contacted the older person, asking him or her whether he or she wanted to participate in the study. Among the older persons, seven were men and eight were women, aged 76-101 years (median $=86$ years). For a description of the sample, see Table 1 .

The interviews lasted between 46 and $147 \mathrm{~min}$ (median $=72 \mathrm{~min}$ ) and were conducted between February 2015 and July 2016. The interviews were of a narrative nature, and after an initial conversation about who we were and why we were there, the informants were asked about their experiences of loneliness in general. Thereafter, the concept of existential loneliness was introduced as follows:

We are particularly interested in your experiences of a deeper feeling of loneliness, called existential loneliness, a feeling that can come and go and be more or less intense. Could you please describe a situation when you experienced existential loneliness?

The older persons were interviewed by researchers other than the authors of this article, within the LONE study team. For a more detailed description of the interviews, see Sjöberg et al. ${ }^{16}$

Interviews with significant others. In connection with the interview, the older persons were asked if they had anyone who was close to them and who might agree to be interviewed. If the older person gave the name of a significant other, that name was communicated to H.L. (the first author). The significant other was then contacted by telephone by H.L., who inquired whether he or she would agree to receive a letter with 
information about the study. A couple of days after the letter had been sent out, the significant other was contacted again by telephone and asked whether he or she wanted to participate. Four of the older persons gave names of two significant others while 11 of the older persons gave only one name of a significant other. Altogether, 20 significant others were identified and asked to participate; 1 declined, which resulted in 19 persons agreeing to participate. All the significant others characterised their relation to the older person as close or very close. The interviews were individual, except one that was done with a couple. Among the significant others, 6 were men and 13 were women, aged 49-86 years (median $=63$ years). The interviews lasted between 40 and $90 \mathrm{~min}($ median $=51 \mathrm{~min})$ and were conducted between February 2015 and August 2016. For a description of the sample, see Table 1. The interviews were of a narrative nature, and after an initial conversation about loneliness in general, the concept of existential loneliness was introduced as follows: 'We are, in particular, interested in a deeper feeling of loneliness, called existential loneliness, a feeling that can come and go. Can you try to remember any situation when you perceived that your ... experienced this kind of loneliness?' For a more detailed description of the interviews, see Larsson et al. ${ }^{17}$

Field notes. According to $\mathrm{Yin}^{27}$ a case study is interested in how a phenomenon is revealed in its context and therefore the field notes were important. After each interview with the older persons, field notes were taken by the researchers who did the interviews. The field notes were important in order to understand the context and focused on three aspects: (1) the physical environment such as living in older houses with high ceilings close to the city centre, smaller houses in the countryside or in a nursing home where material belongings bore witness of another life; (2) the atmosphere during the interview, such as if they wanted us to have some coffee, had laid the table with their finest china or merely wanted to talk to us; and (3) the researcher's thoughts and impressions of the interview situation, such as whether the older persons found it difficult to make their voice heard or to find words to express their experiences.

\section{Analysis}

In accordance with Yin, ${ }^{27}$ the next step was to select cases. In this study, a case was composed of the narratives of one older person, his or her significant other(s) and the field notes. The following step was to design a protocol ${ }^{27}$ that focused on contrasts in experiences and perceptions of existential loneliness. Thus, the interviews with the older persons, the interviews with their significant others and the field notes were read as a unit. Each of the older persons' and their significant others' narratives and the field notes was condensed into a reduced narrative with focus on the older person's context and on his or her experiences of existential loneliness, and significant others' perception of the same. This procedure resulted in 15 constructed narratives totalling about 40 pages.

The 15 constructed narratives were analysed using Braun and Clarke's ${ }^{28}$ guide as follows. The narratives were read repeatedly in order to become familiar with the text. This step was done independently by the four authors, who then came together to compare and contrast their impressions of the text. This was followed by the first author coding meaning units in the text that were related to the aim. The codes were thereafter discussed among the authors until agreement was reached and grouped into themes. The analysis moved back and forward between the 15 constructed narratives, cross-case conclusions and the three themes. For an example of meaning units and themes, see Table 2. The themes can be seen, according to Yin, ${ }^{27}$ as drawing cross-case conclusions. Based on the three themes, three new cross-case narratives were constructed to illustrate the contrast between older people's experiences and their significant others' perceptions of existential loneliness. An illustration of the procedure in the analysis is presented in Figure 1. 
Table 2. Extracts from raw data to exemplify the themes.

\begin{tabular}{|c|c|c|}
\hline Older person & Significant other & Theme \\
\hline 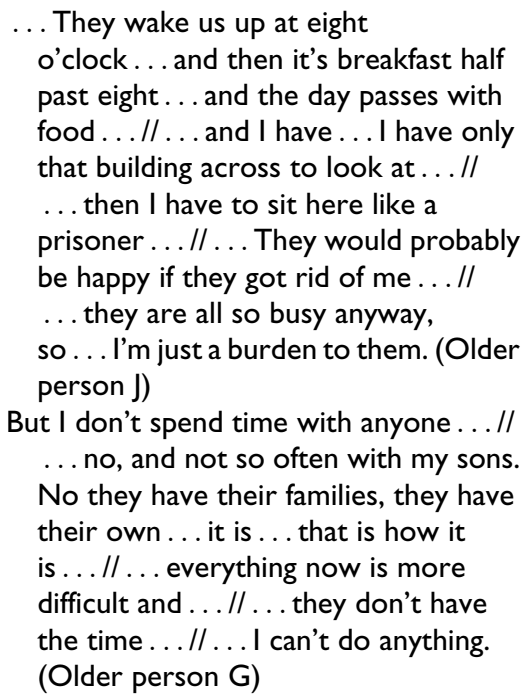 & $\begin{array}{l}\text {.. choir was there and this and } \\
\text { that ... things happen, they try to } \\
\text { provide activities and are efficient } \\
\text { with . . . some quiz and such things ... I } \\
\text { think that there should be more of } \\
\text { those things, I think that it's even more } \\
\text { important than the care itself . . .// } \\
\text {... they should take her } \\
\text { outdoors ... go for walks ... they } \\
\text { should ... go for outings ... then, she } \\
\text { would feel much better. (Child to J) } \\
\text { And then we pick up the crossword- } \\
\text { puzzle, it's very good for your brain, to } \\
\text { keep it working, don't care if you can't } \\
\text { breathe, you can at least solve the } \\
\text { crossword-puzzle. More of that, oh } \\
\text { yes! (Child to G) }\end{array}$ & $\begin{array}{l}\text { Meaningless waiting in contrast } \\
\text { to lack of activities }\end{array}$ \\
\hline 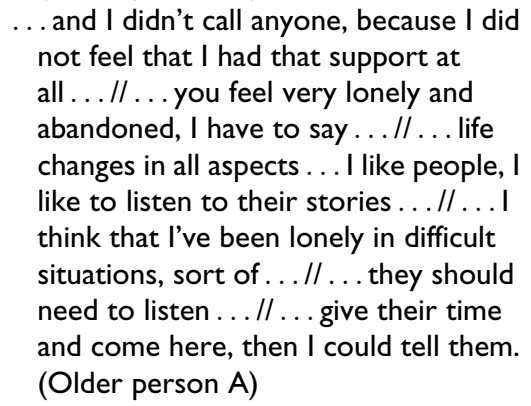 & $\begin{array}{l}\text {... she doesn't prioritise people who } \\
\text { want to visit her, and that's people } \\
\text { whom she herself has chosen...// } \\
\text { or... she could join us getting out, and } \\
\text { that could be nice? But no... no, then } \\
\text { she doesn't want to... (Niece to A) }\end{array}$ & $\begin{array}{l}\text { Longing for a deeper } \\
\text { connectedness in contrast to } \\
\text { not participating in a social } \\
\text { environment }\end{array}$ \\
\hline $\begin{array}{l}\text {. we go together and drink coffee and } \\
\text { similar ... that is those who live } \\
\text { here... yes, several of them and that is } \\
\text { nice and so, but it's not ... when l'm } \\
\text { back, l'm still lonely... . / . . this feeling } \\
\text { of loneliness ... that is what I also think } \\
\text { about when l've turned around in bed, I } \\
\text { could have had another someone lying } \\
\text { there in my room ... (Older person E) }\end{array}$ & $\begin{array}{l}\text { They need ... they need someone who } \\
\text { just sits down to have a cup of coffee and } \\
\text { talk with them ...// . . and sort of bring } \\
\text { them back from loneliness and } \\
\text { depression and those things that often } \\
\text { come along with that. But when they just } \\
\text { say no ...// ... It's just do the best you } \\
\text { can on your own ... //... they don't } \\
\text { want to let anyone inside. (Child to E) }\end{array}$ & \\
\hline $\begin{array}{l}\text {. partly how is it supposed to go now? } \\
\text { And partly how others experience } \\
\text { that ... I mean, relatives and friends } \\
\text { and such ... That you ... that ... is } \\
\text { a ... fear to be exposed ... to be on } \\
\text { your own ... that's not a situation you } \\
\text { think about as long as you are } \\
\text { healthy... . . . . you gradually }\end{array}$ & $\begin{array}{l}\text { Well, to have to run every time ... as } \\
\text { soon as he says ... he calls if it's } \\
\text { anything from that he can't reach the } \\
\text { glass to that he doesn't ... //. We can't } \\
\text { discuss things in the same way that we } \\
\text { used to ... instead he sorts of turns } \\
\text { inwards ... I/ ... this is how ... l'm the } \\
\text { one who asks, l'm the one being }\end{array}$ & $\begin{array}{l}\text { Restricted freedom in contrast } \\
\text { to given up on life }\end{array}$ \\
\hline
\end{tabular}


Table 2. (continued)

\begin{tabular}{|c|c|c|}
\hline Older person & Significant other & Theme \\
\hline $\begin{array}{l}\text { experience it, you sort of feel after a } \\
\text { year or so... before I could do that } \\
\text { very well, but now it's deteriorating, } \\
\text { and that results in that you gradually } \\
\text { maybe experience this loneliness } \\
\text { differently... I/ ... To not ... be able } \\
\text { to participate in the daily life. (Older } \\
\text { person F) }\end{array}$ & $\begin{array}{l}\text { active ...//... he doesn't take any } \\
\text { initiatives by himself ... // ... but come } \\
\text { on, you have to. (Partner to } \mathrm{F} \text { ) }\end{array}$ & \\
\hline $\begin{array}{l}\ldots \text { I'm pathetic as I'm, that's the way I } \\
\text { feel ... I/... I take my pills every } \\
\text { day ... so that I can sleep... and it } \\
\text { affects me, feeling ... really... down, } \\
\text { so to say. But that is actually too } \\
\text { weak... it affects me totally, my whole } \\
\text { life nowadays ... and that, you have to } \\
\text { understand ... . . .. my worst feelings } \\
\text { are connected to that house, that we } \\
\text { had to leave it, that ... is sort of the } \\
\text { largest in this whole, that I have been } \\
\text { forced to do. (Older person } M \text { ) }\end{array}$ & $\begin{array}{l}\text { He's a bit lazy when it comes to exercise, } \\
\text { so I tell him, sometimes I say that he } \\
\text { needs to exercise his arms ... but it's } \\
\text { difficult, so we keep on anyway and I } \\
\text { say that you have to understand that, } \\
\text { that our goal is that you should be able } \\
\text { to get out of bed every morning and } \\
\text { not remain in bed, but to be up and get } \\
\text { dressed, even if you just sit in the } \\
\text { wheel-chair, that is what we need to } \\
\text { aim at. And I nag at him, now you have } \\
\text { to, you see... and pull his arms, but he } \\
\text { actually should be able to do much } \\
\text { more. (Sibling to M) }\end{array}$ & \\
\hline
\end{tabular}

\section{Ethical approval and consent to participate}

The study was performed in accordance with the ethical guidelines by Helsinki Declarations ${ }^{29}$ and approved by the Ethical Review Board, Lund, Sweden (Reg. no. 2014/652). The informants, both the older persons and their significant others, received oral and written information about the aim of the study and about the procedure, together with a guarantee of confidentiality. They all gave both verbal and written consent to participate. It was made clear to the informants that they could withdraw from the study at any time and they were informed that their participation or their withdrawal would not affect the care in any manner. A risk was that the frail older persons would be exposed to too much stress during the interviews, and therefore it was important to be sensitive and not force the older persons to say more than they felt was possible. Permission to audiotape the interview was obtained from the informants. Different people interviewed the older persons and their significant others for ethical reasons such as integrity. If significant others asked what the older person had talked about, we could honestly say that we did not know. For this study, we looked at the pairs (older person together with their significant other), but the findings are presented at a group level to guarantee confidentiality.

\section{Findings}

Below, the narratives of the older persons, their significant others and the field notes are connected and presented in the shape of three themes that contrast their experiences and perceptions of existential loneliness. The themes were Meaningless waiting in contrast to lack of activities, Longing for a deeper connectedness in contrast to not participating in a social environment and Restricted freedom in contrast to given up on life. 


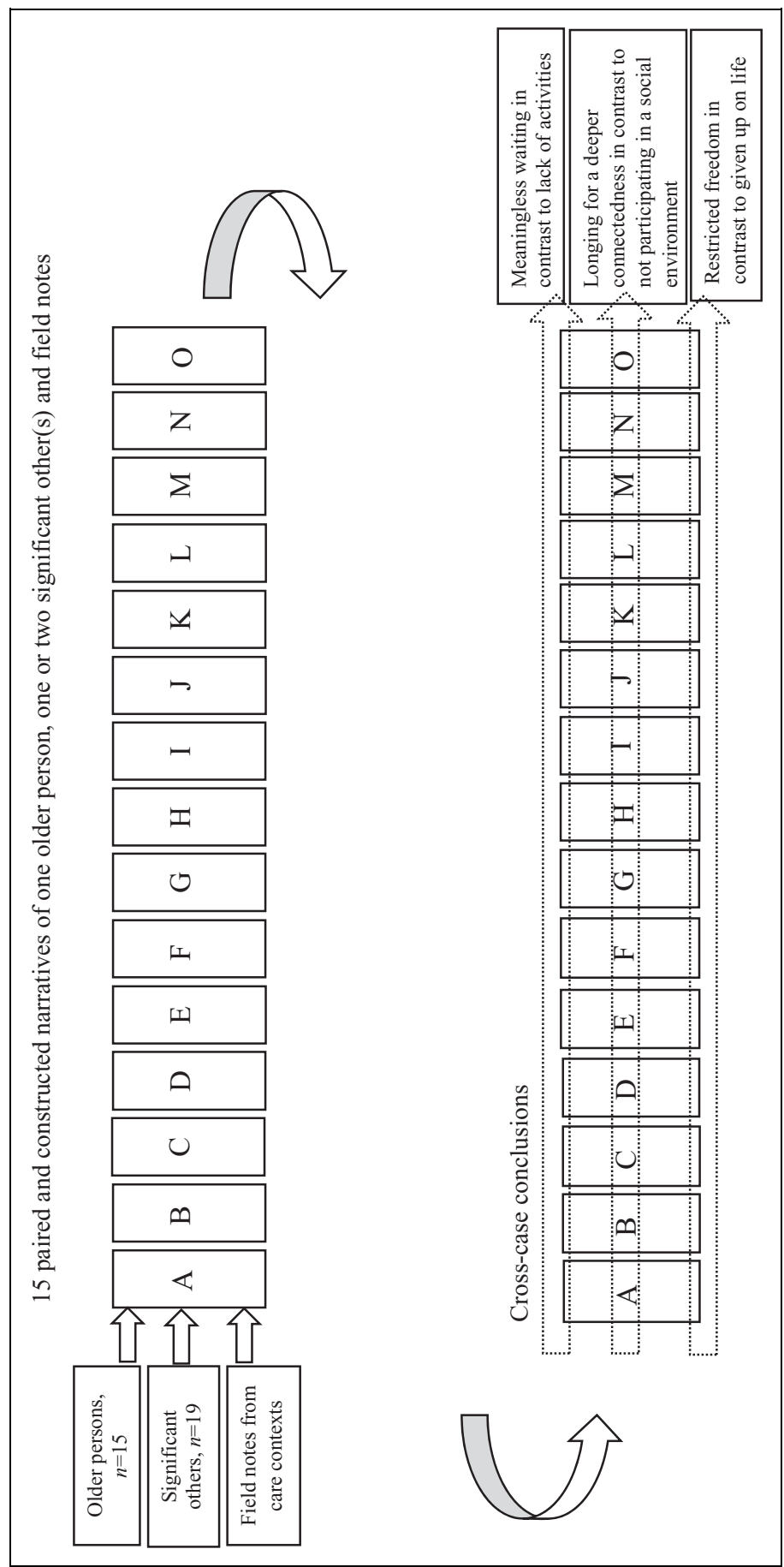

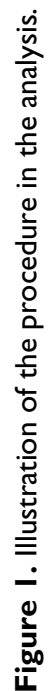




\section{Meaningless waiting in contrast to lack of activities}

The older persons describe how they are in a phase in life that consists of waiting. They are continuously waiting - for health care staff, for their significant others, for help getting to the toilet and for the possibility to go outside. They describe how waiting makes them feel that their life has become meaningless, empty and isolated, and such feelings give rise to existential loneliness. Significant others also relate the older persons' existential loneliness to feelings of meaninglessness and worthlessness but in relation to physical limitations and argue that it is the lack of suitable activities for older persons that triggers existential loneliness. In their endeavours, they try to encourage the older person to participate in activities and suggest that this could make existential loneliness decrease. However, the older persons do not express a longing for activities but rather a desire to be of importance to someone else. They describe how no one does things together with them but only for them. This theme is illustrated below by 'Martin'.

Cross-case narrative. Martin is 92 years old. He lives alone in a small apartment at an assisted living facility. He feels that his life has no meaning for anyone else anymore, which makes him experience existential loneliness. He feels that no one asks for his opinion or knowledge anymore. His significant others believe that Martin's existential loneliness relates to his physical limitations making him unable to take part in activities as he used to do. Martin spends most of his time in bed, where he has a clock, a TV and a music system. The clock is a constant reminder of how time passes even though Martin's life has become silent and characterised by waiting. His significant others perceive that Martin is doing well and that he is being taken good care of, while Martin himself thinks that his day is all about waiting for help from others. He feels that no one wants to do things together with him, only for him. Earlier in life, Martin experienced his home as a place for rest and tranquillity after work and travels. Now, his home has become a place for waiting rather than calmness. Before, he was the one everyone else was waiting for, and now he is the one who is waiting. For his significant others, these feelings of tiredness and waiting that Martin describes are disguised; instead they perceive that Martin needs something to do that keeps him busy, while Martin talks about the longing to be of importance to someone else.

\section{Longing for a deeper connectedness in contrast to not participating in a social environment}

The older persons describe how they feel excluded when they are among people whom they do not feel any connectedness with, or when they have no one to share essentials in life with. They describe how such situations give rise to existential loneliness. Significant others also relate the older persons' existential loneliness to emptiness due to losses of friends, family and places but rather they talk of the importance of having a social environment where it is possible to come together with people, since they believe that older persons experience existential loneliness if they do not socialise with others. Significant others describe how they often visit or call the older persons, but despite this, the older persons claim that few people, and sometimes no one, have deep and meaningful conversations with them. The conversations they refer to are about events in society, politics or news rather than daily things like the weather or when dinner is served. As the older persons gradually lose their long-term relationships with friends and family, significant others try to construct a new social environment for them. Significant others perceive that older persons' existential loneliness relates to their withdrawal and that they therefore end up without a social environment. This theme is illustrated below by 'Lilly'.

Cross-case narrative. Lilly is 83 years old and has lived in a nursing home ever since her husband died a couple of years ago. She feels that her life has become so hard since her husband died because she has no one to share difficult decisions with. An example of this is when she was at the hospital and had to decide 
whether she wanted a treatment or not. The doctors had discovered a tumour in her back and gave her different alternatives of treatment to choose between. She felt that she had no one to talk to about what she should do and she felt very lonely in her decision. Lilly experiences existential loneliness when she has no one to share moments like that with. She describes her experience like a new kind of loneliness, a loneliness that she has never felt before. Her significant others, however, perceive that Lilly's existential loneliness has to do with her being left out of the community at the nursing home and believe that Lilly could leave her room more often to spend time with the other residents. However, to be left out of the community is not something that Lilly talks about. She misses someone to share essentials in life with and that induces a feeling of existential loneliness. Lilly feels that her significant others have no interest in what interests her, namely art and music. Instead they suggest, for example, that she watches TV so that she has something more 'ordinary' to chat about, which they believe could help her integrate into the community at the nursing home.

\section{Restricted freedom in contrast to given up on life}

The older persons experience existential loneliness when they are not given the opportunity to express their wishes or choose by themselves in their everyday life, since they are dependent on other people's help. Significant others also relate the older persons' existential loneliness to dependency, but they do not talk about how the older person can no longer choose by themselves. They do not perceive the situation in a similar way; that is, they do not relate the older person's situation to restricted freedom but instead they relate the older person's existential loneliness to him or her having given up on life and lost his or her fighting spirit. This contrast between the attitude of the older person and that of their significant other also includes the material world. When the older person can no longer choose where to live, this gives rise to existential loneliness. Significant others, on the contrary, in their endeavours, want to find a comfortable home for the older person. They try to compensate the older person and facilitate things for them by helping them make decisions in daily life. However, the older persons feel that decisions are made for them and not together with them, which increases their existential loneliness. This theme is illustrated below by 'Jenny'.

Cross-case narrative. Jenny is 86 years old and lives alone in an apartment on the ground floor. She does not want to live in this apartment, but she feels that she has no other choice, and therefore she experiences existential loneliness. Jenny describes how throughout her life she has moved and changed her life depending on the circumstances, but now she can no longer choose where to be, and to feel like this is a new situation for her. The strategies she always used before when dealing with different situations in life are no longer possible. She feels that she cannot influence her daily life since she is dependent on other peoples' help. She can look out through the windows, but she cannot get outside. Her significant others instead relate Jenny's existential loneliness to how she has given up on life and not to her lost freedom. They believe that it was good for her to move and that those who got her to do so did well. The significant others perceive the apartment on the ground floor as a comfortable place for Jenny, and they believe that she is doing well at this place with windows in several directions. However, Jenny yearns for the place where she believed she could live for the rest of her days. If she had the opportunity to choose, she would move back again. She had to get rid of most of her material belongings when she moved. For Jenny, every belonging was a memory of her life and made her feel at home and anchored in her life, connected to the people she knew and the travelling she had done, while her significant others perceive that it was nice for her to get rid of a lot of her belongings. Jenny thinks it is so hard and she feels reluctant to stay at this place and does not recognise herself in her new life. Her significant others continue instead to talk of the importance of not giving up and they do not perceive the existential loneliness that Jenny feels when she has no possibility to choose for herself. 


\section{Discussion}

The findings from this study highlight contrasts between older persons' experiences and significant others' perceptions of existential loneliness. These contrasts were identified as (1) Meaningless waiting in contrast to lack of activities, (2) Longing for a deeper connectedness in contrast to not participating in a social environment and (3) Restricted freedom in contrast to given up on life. The findings can be seen in the light of the existential psychologist Emmy van Deurzen's ${ }^{30}$ description of different dimensions in a person's life world. First, the physical dimension 'Umwelt' ${ }^{30}$ is characterised by different paces of life. In the present study, the older person's everyday life is characterised by waiting while their significant others often have a busy everyday life with family, friends and hobbies. Second, the social dimension 'Mitwelt ${ }^{30}$ is characterised by different processes. In the present study, the older persons have gradually lost their social environment, as they can no longer participate in such an environment, or have lost longterm relationships while their significant others often have, for instance, a social environment where they belong. Third, the personal dimension 'Eigenwelt ${ }^{30}$ is characterised by different roles. In the present study, the older persons, due to increasing bodily and mental limitations, are gradually losing their roles in the family and in society while their significant others have often retained a significant and meaningful role in the family and in society. This, in turn, reflects the different perspectives older people and their significant others have, and might explain why significant others have difficulties in taking the older persons' perspective on a deeper level.

One tension between frail older persons and their significant others occurs when they have different views of how to find meaning in life and thereby reduce existential loneliness. Significant others position themselves from their own perspective to determine what brings meaning in the older person's life. The results showed that the older persons' daily life was permeated by a continuous waiting, which resulted in a feeling that their life was meaningless. Significant others, instead, talked about the need for activities as a means to bring meaning to the older person's life. However, the older persons did not miss general activities but rather activities that gave a deeper sense of meaning. Frankl ${ }^{9}$ describes how the ability to find meaning in existence is essential. If older persons have trouble finding meaning in their existence, there is a risk that their well-being will decrease, and it might decrease further if they are not given the opportunity to discuss their thoughts and feelings on a deeper level. ${ }^{31}$ In addition, other studies have shown that there is a link between, for example, lack of a meaningful life and depression. ${ }^{18}$ Bergum and Dossetor ${ }^{32}$ describe the importance of following a person closely and being genuinely interested in recognising the other person's wants and wishes. In addition, Martin Buber ${ }^{33}$ describes the importance of listening, not only to the spoken words but also to the facial expressions, the tone of voice and the unspoken words. ${ }^{33}$ When older persons no longer have the ability to create their own meaning, significant others and health care staff are essential resources. Since the older persons in this study particularly talked about the importance of being, and not doing, the challenge seems to be to account for the older person's need of being. In a study regarding nurse assistants' experiences of providing palliative care in municipal residential care settings, the findings reveal the dilemma of focusing on the being, that is, the relation, when the doing, that is, the task, has the highest priority. In addition, even if health care staff identify relational and existential needs, the organisation can be a barrier to meet those needs when the task-oriented actions are promoted. ${ }^{34}$ How to recognise and support a meaningful existence for people who are old and frail is thus something that needs to be given high priority in health care settings in order to promote well-being and a meaningful life.

Another tension between older persons and their significant others occurs when they have different views of how to feel connected in life. The results showed that significant others talked about 'being connected' in terms of having many social contacts and suggested more social activities in nursing homes to reduce existential loneliness. However, what prevented older persons from feeling connected was the lack of close relations where they could have deep conversations about meaningful topics. Other studies have revealed 
that there are periods in life when it is difficult to feel connected, for example, in combination with a severe illness ${ }^{14}$ or in a new context, something that has been expressed as 'feeling lonely in an unfamiliar place'. 31 This is in line with the thoughts of Tillich, ${ }^{8}$ who has described the essence of how to feel connected in terms of either 'taking part' or 'being a part', where both aspects are needed in order to feel connected in life. The findings from our study show that the older persons are 'taking part' to a larger extent than 'being a part'. Even if the significant others endeavour to connect the older persons to a new social context, it may be difficult for the older persons to feel that they really are 'being a part'. The tension can also be understood in the light of the two parties being in different phases of life. The older persons are in their last phase in life, termed the 'ninth stage' by Erikson and Erikson. ${ }^{35}$ This stage is characterised as a balancing act between negative and positive aspects in life, where the negative aspects are increasingly in focus. ${ }^{35}$ For health care staff, the awareness of different phases in life is essential; otherwise it might be difficult for frail older persons to feel understood in their existential loneliness. For older persons to feel connected, connectedness in a deeper sense is vital.

Finally, yet another tension between the older persons and their significant others occurs when they have different views of freedom. The results showed that significant others often took on the role of decisionmaker for the older persons, perceiving that their help made it easier for the older person to manage his or her situation. However, for the older persons, existential loneliness arose when they felt that they no longer had a choice, when someone else took decisions for them and not together with them. Bergum and Dossetor $^{32}$ describe the role of significant others as being both that of a witness and a decision-maker. A witness is the one who 'knows something' and a decision-maker is the one who makes decisions for others. Significant others are important, both as witnesses and as decision-makers, and several studies highlight the importance of health care staff listening to significant others. ${ }^{4-6}$ However, there is a risk that this will be at the expense of the older person's voice. Not being listened to, or being unable to make one's voice heard, can result in feelings of powerlessness and lack of autonomy. ${ }^{32}$ Freedom of choice and freedom to influence one's own life are crucial aspects of autonomy. ${ }^{32}$ For significant others and health care staff, it is important to give older persons in need of care the opportunity to choose. Related to this is trust - a key value in the care of older persons. However, trust is a sensitive concept and grows in the presence of warm and empathic relations. ${ }^{33}$ An interview study by Tuominen et al. ${ }^{36}$ shows that it is not the life-changing events that make older persons feel autonomous and free but the daily events, such as control of one's bedtime, dressing, privacy and social life with relatives. Therefore, it seems important to preserve older people's independence and autonomy as far as possible, even concerning daily activities. How to involve frail older persons and make their voices and choices heard, when they are dependent on help from others, is a critical topic for ethical discussions among health care professionals.

\section{Methodological considerations}

There are limitations to this study. Even if it was the older persons themselves who gave the name/s of significant other(s), there is a risk that the significant others were not as close to the older persons as they needed to be in order to be able to interpret the older person's existential loneliness; this could potentially reduce credibility. ${ }^{37}$ However, all of the significant others characterised their relation to the older person as close or very close. Another limitation is that there is no clear consensus on the concept of existential loneliness. This may be seen as a weakness and a challenge to the credibility of our data. ${ }^{37}$ To counter this possibility, we introduced the concept to the informants in the written information and started the interviews, both with the older persons and their significant others, with the description of existential loneliness as a deeper feeling of loneliness. In addition, the interviews were done by two persons, one junior researcher and one senior researcher, who were both familiar with conversations about existential issues. Since the first author (H.L.) did the interviews with the significant others but not with the older persons, there was a risk 
that her pre-understanding of the significant others' views affected the interpretations of the older persons' views in the analysis. ${ }^{37}$ To minimise this risk, it was vital to listen to the interviews with the older persons and to read the transcriptions and the field notes. Another measure was to involve the second author (A.K.E.), who had not taken part in any of the interviews and therefore was not influenced by any interview beforehand. In addition, to safeguard confirmability, ${ }^{37}$ the four authors have different professional backgrounds, including caring science, theology, geriatric nursing and human geography. All four authors took part in the analysis and discussed the themes until an agreement was reached. In order for the researchers' interpretations to be verifiable, ${ }^{37}$ every step in the methods has been described and illustrated in a figure, extracts from raw data have been presented in a table and a narrative has been extracted to exemplify each theme. Concerning the transferability ${ }^{37}$ of the results, the informants in this study were identified within a Swedish health care context and the study had no participation of people with a migrant background, except for one of the significant others, which might limit the transferability. However, the informants were identified within different health care contexts to increase variation, which might strengthen the transferability to several settings.

\section{Clinical implications}

This study highlights the importance of listening to both the older persons' experiences and their significant others' perceptions, but in order to handle ethically difficult situations, where health care staff have to choose between alternative courses of action, it is of great importance to be aware of whose voice the care is based on. One way to bridge the gaps in these revealed contrasts could be a more relation-centred approach ${ }^{1}$ where both the frail older persons' story and their significant others' voices are given equal weight. In the present study, the findings reveal the importance of listening to both the frail older person and the significant other(s) rather than only one perspective or favouring one perspective over the other. Such knowledge is important in the provision of care and could be of use as a basis for ethical reflections in the care of older people and in the encounter with significant others.

\section{Conflict of interest}

The author(s) declared no potential conflicts of interest with respect to the research, authorship and/or publication of this article.

\section{Funding}

The author(s) disclosed receipt of the following financial support for the research, authorship, and/or publication of this article: This study is a part of the LONE study, funded by grants from the Vardal Foundation and the Research Platform for Collaboration for Health at Kristianstad University, the Crafoord Foundation and the Greta and Johan Kock Foundation, and the Gyllenstiernska Krapperup Foundation.

\section{References}

1. Witkamp E, Droger M, Janssens R, et al. How to deal with relatives of patients dying in the hospital? Qualitative content analysis of relatives' experiences. J Pain Symptom Manage 2016; 52: 235-242.

2. Abrahamsson K, Bernard B, Magnabosco L, et al. The experiences of family members in the nursing home to hospital transfer decision. BMC Geriatr 2016; 16: 184.

3. Dyrstad DN, Laugaland KA and Storm M. An observational study of older patients' participation in hospital admission and discharge - exploring patient and next of kin perspectives. J Clin Nurs 2015; 24: 1693-1706.

4. Caspari S, Lohne V, Rehnsfeldt AW, et al. Dignity and existential concerns among nursing homes residents from the perspective of their relatives. Clin Nurs Stud 2014; 2: 22-33. 
5. Andershed B. Relatives in end-of-life care-part 1: a systematic review of the literature the five last years, January 1999-February 2004. J Clin Nurs 2006; 15: 1158-1169.

6. Funk L, Stajduhar K, Toye C, et al. Part 2: home-based family caregiving at the end of life: a comprehensive review of published qualitative research (1998-2008). Palliat Med 2010; 24: 594-607.

7. Bolmsjö I, Edberg AK and Sandman L. Everyday ethical problems in dementia care: a teleological model. Nurs Ethics 2006; 13: 340-347.

8. Tillich P. The courage to be. New Haven, CT: Yale Nota Bene, 2000.

9. Frankl VE. Man's search for meaning: an introduction to logotherapy. London: Hodder \& Stoughton, 1987.

10. Yalom ID. Existential psychotherapy. New York: Basic Books, 1980.

11. Mok E, Lau K, Lam W, et al. Health care professionals' perceptions of existential distress in patients with advanced cancer. $J$ Adv Nurs 2010; 66: 1510-1522.

12. Mayers AM and Svartberg M. Existential loneliness: a review of the concept, its psychosocial precipitants and psychotherapeutic implications for HIV-infected women. Br J Med Psychol 2001; 74: 539-553.

13. Ettema EJ, Derksen LD and van Leeuwen E. Existential loneliness and end-of-life care: a systematic review. Theor Med Bioeth 2010; 31: 141-169.

14. Sand L and Strang P. Existential loneliness in a palliative home care setting. J Palliat Med 2006; 9: 1376-1387.

15. Nyström M. Aphasia - an existential loneliness: a study on the loss of the world of symbols. Int J Qual Stud Heal 2006; 1: 38-49.

16. Sjöberg M, Beck I, Rasmussen B, et al. Being disconnected from life - meanings of existential loneliness as narrated by frail older people. Aging Ment Health 2018; 22: 1357-1364.

17. Larsson $\mathrm{H}$, Rämgård $\mathrm{M}$ and Bolmsjö I. Older persons' existential loneliness as interpreted by their significant others - an interview study. BMC Geriatr 2017; 17: 138.

18. van Wijngaarden E, Leget C and Goosensen A. Ready to give up on life: the lived experience of elderly people who feel life is completed and no longer worth living. Soc Sci Med 2015; 138: 257-264.

19. Karlsson M, Friberg F, Wallengren C, et al. Meanings of existential uncertainty and certainty for people diagnosed with cancer and receiving palliative treatment: a life-world phenomenological study. BMC Palliat Care 2014; 13: 28.

20. Allen R and Butler E. Addressing moral distress in critical care nurses: a pilot study. Int J Crit Care Emerg Med 2016; 2: 015.

21. International Council of Nurses (ICN). The ICN code of ethics for nurses, http://www.icn.ch/images/stories/ documents/about/incode/ (2008, accessed 27 March 2018).

22. Sundström M, Edberg AK, Rämgård M, et al. Encountering existential loneliness among older people: perspectives of health care professionals. Submitted. 2017.

23. Lukas A, Niederecker T, Günther I, et al. Self- and proxy report for the assessment of pain in patients with and without cognitive impairment: experience gained in a geriatric hospital. Z Gerontol Geriatr 2013; 46: 214-221.

24. Robertson S, Cooper C, Hoe J, et al. Proxy rated quality of life of care home residents with dementia: a systematic review. Int Psychogeriatr 2017; 29: 569-581.

25. Edberg AK and Bolmsjö I. Study protocol: exploring existential loneliness among frail older people. The development phase of the LONE study. Submitted. 2017.

26. Medical Research Council. Developing and evaluating complex interventions: new guidance. London: Medical Research Council, 2008.

27. Yin RK. Case study research - design and methods. Thousand Oaks, CA: Sage, 2003.

28. Braun V and Clarke V. Using thematic analysis in psychology. Qual Res Psych 2006; 3: 77-101.

29. WMA Declaration of Helsinki, http://www.wma.net/policies-post/wma-declaration-of-helsinki-ethical-principlesfor-medical-research-involving-human-subjects/ (2008, accessed 27 March 2018).

30. van Deurzen E. Existential counselling in practice. London: Sage, 1998. 
31. Österlind J, Ternestedt BM, Hansebo G, et al. Feeling lonely in an unfamiliar place: older people's experiences of life close to death in a nursing home. Int J Older People Nurs. Epub ahead of print 14 September 2017. DOI: 10.1111/opn. 12129.

32. Bergum V and Dossetor J. Relational ethics: the full meaning of respect. Hagerstown, MD: University Publishing Group, 2005.

33. Buber M. The life of dialogue. New York: Routledge, 1955/2002.

34. Beck I, Törnquist A, Broström L, et al. Having to focus on doing rather than being - nurse assistants' experience of palliative care in municipal residential care settings. Int J Nurs Stud 2012; 49: 455-464.

35. Erikson EH and Erikson JM. The life cycle completed. New York; London: Norton, 1982/1998.

36. Tuominen L, Leino-Kilpi H and Suhonen R. Older people's experiences of their free will in nursing homes. Nurs Ethics 2016; 23: 22-35.

37. Shenton AK. Strategies for ensuring trustworthiness in qualitative research projects. Educ Inf 2004; 22: 63-75. 